\title{
Evaluation of In Vivo Transfection Efficiency of Eudragit Coated Nano- particles of Chitosan-DNA: A pH-sensitive System Prepared for Oral DNA Delivery
}

\author{
Sedigheh Momenzadeh ${ }^{1}$; Abdorrahim Sadeghi ${ }^{2}$; Nasimeh Vatandoust ${ }^{3}$; Rasoul Salehi ${ }^{3,}$ \\ ${ }^{1}$ Department of Medical Biotechnology, Faculty of Medicine, Arak University of Medical Sciences, Arak, IR Iran \\ ${ }^{2}$ Department of Biochemistry and Genetics, Molecular and Medicine Research Center, Faculty of Medicine, Arak University of Medical Sciences, Arak, IR Iran \\ ${ }^{3}$ Department of Genetics and Molecular Biology, School of Medicine, Isfahan University of Medical Sciences, Isfahan, IR Iran \\ ${ }^{*}$ Corresponding Author: Rasoul Salehi, Department of Genetics and Molecular Biology, School of Medicine, Isfahan University of Medical Sciences, Isfahan, IR Iran. Tel:+98-3137922487. \\ Fax:+98-3136688597, E-mail: r_salehi@med.mui.ac.ir
}

Received: December 12, 2013; Revised: March 3, 2015; Accepted: March 18, 2015

\begin{abstract}
Background: Success of any gene therapy protocol relies mostly on using an efficient carrier to direct nucleic acid to the place of action. The system should also have transfection ability at release site. Different routes are available for delivering genetic materials to the target organs, amongst them; oral delivery is particularly attractive for certain reasons. However, serious obstacles, like acidic environment of stomach and presence of protease and nuclease enzymes in gastrointestinal (GI) tract, make oral route a highly challenging option.

Objectives:The present study suggests preparation of gene nanoparticles(NPs) of chitosan within a layer of Eudragit L100 for oral delivery of nucleic acid. The nanoparticles have some features both in size and polymer properties that can be penetrating enough to transfect epithelial layer cells of intestine and protect the entrapped materials against stomach harsh condition.

Materials and Methods: In this experimental study, conducted in Iran, particles were prepared by coacervation technique followed by encapsulation of nanoparticle within a coat of Eudragit L100 using solvent evaporation technique. Formulation behavior was monitored both in vitro and in vivo. Stability of particle construction and release profile of DNA were examined at $\mathrm{pH}$ of \pm 0.8 environ pKa of Eudragit. Size and zeta potential of particles were measured. To demonstrate transfection efficiency of the constructed carrier, reverse transcription polymerase chain reaction (RT-PCR) was carried out using human insulin specific primers on total RNA extracted from upper part of small intestine of 48-hour post-transfected rats (sampled by simple random selection, $\mathrm{n}=3$ ).

Results: The mean size and zeta potential of particles were $300 \pm 4 \mathrm{~nm}$ and $14 \pm 0.5 \mathrm{mV}$, respectively. Encapsulation of this system was 89.6 $\pm 1.2 \%$. DNA release from batches was less than $12 \%$ at $\mathrm{pH}=5.2$ and more than $60 \%$ at $\mathrm{pH}=6.8$ with significant difference of $\mathrm{P}<0.05$. RT-PCR product confirmed the presence of insulin transcript of $437 \mathrm{bp}$ in upper intestinal extracts of the transfected rats. No band of DNA was seen after RT-PCR of placebo form of nanoparticles received group.
\end{abstract}

Conclusions: Eudragit coated nanoparticle of chitosan is an efficient choice for oral delivery of DNA to upper part of GI tract.

Keywords: Gene Therapy; Delivery of DNA; Nanoparticles

\section{Background}

Oral drug administration is the most convenient and acceptable route of drug delivery for patients. Peptide and protein drugs are administered orally by different carrier systems usually targeting intestines $(1,2)$. Circulating half-life of therapeutic proteins and peptides is so short that necessitates daily administration, while administration of genes encoding the same therapeutic proteins or peptides can be trusted to last longer in vivo. Protein release is also more sustained; therefore, it can reduce the problems of high dose administration.

Gene therapy is the transferring of genetic materials into the bodies' specific cells in order to either correct or retrieve a genetic disorder or act as a supplement for defective genes (3). Most of in vivo gene therapy trials are carried out in an invasive way; therefore, the route of administration has remained a concern in this course (4-7). Oral administration of genetic materials is a very attrac- tive and convenient route, especially when the target is gastrointestinal (GI) tract cells. To achieve this goal, an efficient system of delivery is required to develop. As it is evident, via oral route, nucleic acid should be well protected against the harsh condition of GI tract to reach safely to its destination point of action (8).

The two main impediments of orally delivered genes are intestinal short transit time and $\mathrm{pH}$ of stomach (9, 10). Materials transit time through intestines is limited because of peristaltic activity of the intestine. However, broad absorption surface can make up for that. It might be a problem though, especially in low dose application because this activity decreases the remaining time of materials in the target area and results in less access of materials to epithelial layer. Using mucoadhesive and mucopenetrating materials such as chitosan will increase the material access to the absorption site. Chitosan is a

Copyright ( ) 2015, Iranian Red Crescent Medical Journal. This is an open-access article distributed under the terms of the Creative Commons Attribution-NonCommercial 4.0 International License (http://creativecommons.org/licenses/by-nc/4.0/) which permits copy and redistribute the material just in noncommercial usages, provided the original work is properly cited. 
polymer of deacetylated chitin, commercially available in different molecular weights. Chitosan has been used in DNA delivery, especially DNA vaccines because of its fine encapsulation efficiency (11). The main problem with chitosan is the low resistance of chitosan nanoparticles in low $\mathrm{pH}$ for the sake of amino group protonation. It can lead to loss of a portion of loaded drug in lower $\mathrm{pH}$, hence challenging the success of the gene therapy protocol. Although chitosan is a fine-tuned nanosystem of delivery, it lacks retardation attribute in oral delivery in vivo. Many experiments in this field were carried out by coupling of two polymers (at least one has the feature). Polymers such as Eudragit, hydroxypropyl methylcellulose, alginate, poly- $\varepsilon$-caprolactone are those ones with especial pKa, made them useful for oral delivery $(1,2,12,13)$. By using a retarding system beside chitosan, it seems that we will attain an ideal system for oral delivery of nucleic acid. Eudragit is a copolymer of methacrylate and acid methacrylic. Eudragit L100 dissolves at $\mathrm{pH}=6$ that makes it suitable for intestine delivery purposes (14).

\section{Objectives}

In the present study, we designed an efficient oral delivery system in which 2 types of polymers (chitosan and Eudragit) are combined. Chitosan-eudragit was previously prepared for delivery of sodium diclofenac to colon (15). Here our aim was to evaluate the success of our nanoparticle construct against low pH, like the one in the stomach, and its intestinal cells transfection efficiency. Thus, the difference of DNA release from the batches was evaluated when the batches experience the higher and lower $\mathrm{pH}$ than Eudragit pKa and topical injection of prepared complexes was performed in upper part of rat small intestine. Then we examined functionality of Eudragit coated NPs by RT PCR assay.

\section{Materials and Methods}

This experimental study includes preparation of $\mathrm{pH}$ sensitive nanoparticles of Insulin DNA and in vivo study in rats.

\subsection{Plasmid Amplification and Isolation}

pGIP/Ins plasmid was provided by Burton M. Wice, encoding human insulin (16). Plasmid was propagated in Escherichia coli Top10 and extracted using plasmid extraction kit (Gene Jet plasmid Miniprep kit, Thermo scientific, USA). The quality was examined by gel electrophoresis and DNA concentration was measured by UV absorption at $260 \mathrm{~nm}$.

\subsection{Chitosan-DNA Nanoparticles Synthesis}

Chitosan dilutions between $0.005 \%$ and 0.1\% (Sigma-Aldrich, Munich, Germany) in acetic acid were used to eval- uate the best ratio of chitosan for a fixed concentration of DNA. DNA-chitosan nanoparticles (NPs) were prepared using coacervation method $(17,18)$. Briefly, $0.03 \%$ solution of chitosan in $1 \%$ acetic acid and DNA in 25 mM sodium sulphate with concentration of $100 \mathrm{ng} / \mathrm{\mu L}$ was separately heated at $55^{\circ} \mathrm{C}$. Immediately afterward, the equal volume of each solution was mixed and vortexed at maximum speed for 45 seconds. Nanoparticles were then left at room temperature for 1 hour.

\subsection{Chitosan-DNA NPs Characterization; Polyplex Integrity, Size and Zeta Potential}

Positive zeta potential helps in NPs movement toward negatively charged mucus surface. Nano size particles also increase the possibility of gene transfer to the bottom of intestinal crypts and improve access to the recently differentiated cells.

Interaction of DNA and chitosan leads to the neutralization of DNA charges, hence its electrophoretic mobility will be abolished. Chitosan-DNA integrity was assessed by gel electrophoresis (19). Test complexes were run on $0.7 \%$ agarose gel, stained with DNA Green Viewer, in Tris-Borate-EDTA buffer at $100 \mathrm{v}$ for $30 \mathrm{~min}$. Hydrodynamic size and zeta potential of test complexes were measured by photon correlation spectroscopy (Nano ZS, ZE3600, Malvern Instruments, and Southborough, MA, USA).

\subsection{Polyplex Coating Using Eudragit}

DNA-chitosan nanoparticles have been coated within Eudragit L100 using electrostatic interaction (20). The ratio of coating was based on Khamanga et al. instruction (21). One milligram of Eudragit (Rohm, Dramstadt, $\mathrm{GmbH}$, Germany) was accurately weighed and dissolved in $13.5 \mathrm{~mL}$ organic solvent (acetone:ethanol, ratio of 1:1) (22). Then, $0.2 \mathrm{mg}$ of chitosan-DNA NPs, containing almost $50 \mu \mathrm{g}$ DNA, was drip dropped into organic phase under magnetic stirring condition (emulsion was prepared for 3 in vivo tests). The organic phase of resultant water in oil emulsion was left to evaporate on stirrer (IKA, RH, Germany). The remnant was then centrifuged at $9500 \mathrm{rpm}$ for $30 \mathrm{~min}$. Supernatant was discarded and the pellet was washed twice with deionized water to remove residual organic part, plasmid, or polymers not incorporated into particles (23).

\subsection{DNA Encapsulation Efficiency of Eudragit Coated NPS}

DNA encapsulation efficiency, in NPs coated by Eudragit L100, is the difference between the total amount of DNA used for nanoparticle preparation and the amount of non-entrapped DNA remaining in suspension supernatant after centrifuge (Equation 1). 
Momenzadeh S et al.

3.6. In Vitro Stability Against Acidic $p H$ and Release Profile of Nanoparticles

Dried pellet of coated nanoparticle was divided into two normal saline tubes. In one tube, $\mathrm{pH}$ was adjusted 0.8 unit above the pKa of Eudragit, which is 6, and in another one, 0.8 unit below that.

The tube with pH of 5.2 evaluates the stability of Eudragit coated nanoparticle against acidic pH during 9 hours (considering almost maximum transit time in GI tract) and the tube with $\mathrm{pH}$ of 6.8 evaluates the release profile of DNA from Eudragit batches during the same period of time ( $\mathrm{pH}$ range was selected near Eudragit pKa to evaluate the exact changes in batches' behavior after coating with eudragit). After incubation, the amount of DNA release was measured spectrophotometrically at $260 \mathrm{~nm}$.

\subsection{In Vivo Transfection}

Female Sprague-Dawley rats of $250 \mathrm{~g}$ weight were used in this study (The study is approved by Ethics Committee of Arak University of Medical Sciences approval on May 6th, 2012 by code of 90-124-10). Three animals were housed in each cage under controlled room temperature and humidity with 12:12 hour light-dark cycle according to the guidelines of the Isfahan University of Medical Sciences and fed formal rodent chew. Six rats were divided into two groups of A and B. Group A received Eudragit coated nanoparticles (NPs) as case and group B received a placebo form of NPs (Eudragit-chitosan without DNA loaded) following overnight fasting condition.

Rats were anesthetized by ketamine and the abdomen was cut from beneath the sternum end downward to bring out duodenum. Complexes were applied to duodenum initial part by direct injection. The abdomen and skin were then stitched. Rats of each group were sacrificed 48 hours post NPs administration.

\subsection{RNA Extraction and Reverse Transcription (RT)- PCR}

Initial $5 \mathrm{~cm}$ of small intestine was dissected. The tissue was homogenized under liquid nitrogen and total RNA was isolated by TRIzol Reagent (Invitrogen, Carlsbad, CA, USA) and according to acid guanidium thiocyanate-phenol-chloroform method (24), cDNA was synthesized (cDNA synthesis kit, Thermoscientific, USA) and subjected to PCR reaction using rat $\beta$-actin specific primers to evaluate RNA isolation and cDNA synthesis steps. Human insulin specific primers, amplifying a $437 \mathrm{bp}$ fragment, were then applied to assess the efficiency of gene transfer and expression in small intestine. The product of RT-PCR was then analyzed using agarose gel electrophoresis.

\subsection{Statistical Analysis}

Statistical analysis was performed using SPSS software version 16 . The result were expressed as Mean \pm SD. Effect of nanoparticles properties were statistically analyzed by
Student paired t test with $\mathrm{P}<0.05$ considered as significant difference.

\section{Results}

\subsection{Polyplex Integrity}

Different ratios of chitosan-DNA N/Ps were assessed using agarose gel electrophoresis system. As it is evident in Figure 1, 0.03\% chitosan solution has provided complete protection and resulted in absence of DNA band in gel.

\subsection{Zetasize Analyzing}

Zetasize analyzing revealed the size of N/P complexes to be $300 \pm 4 \mathrm{~nm}$ for $5 \mathrm{kDa}$ chitosan (Figure 2). The charge of prepared nanoparticles were measured to be $+14 \pm 0.5$. This positive charge would be critical for the stability of particles before in vivo application.

4.3. DNA Encapsulation Efficiency, Stability, and Release Profile of Eudragit Coated NPS

\subsubsection{DNA Encapsulation Efficiency}

Based on the amount of DNA used for preparation of nanoparticles $(50 \mu \mathrm{g})$ and the amount of non-entrapped

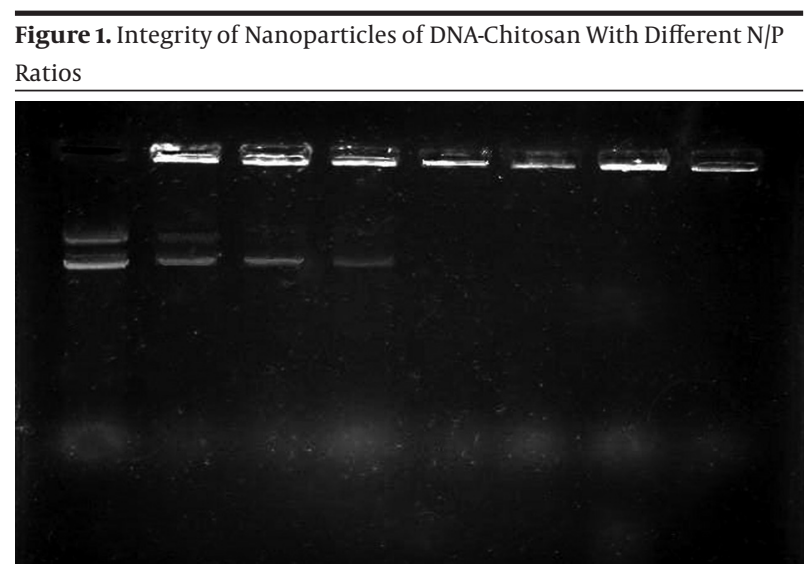

Lanes from left to right: naked plasmid, $0.005 \%$ chitosan, $0.01 \%, 0.02 \%$, $0.03 \%, 0.04 \%, 0.05 \%$, and $0.06 \%$.

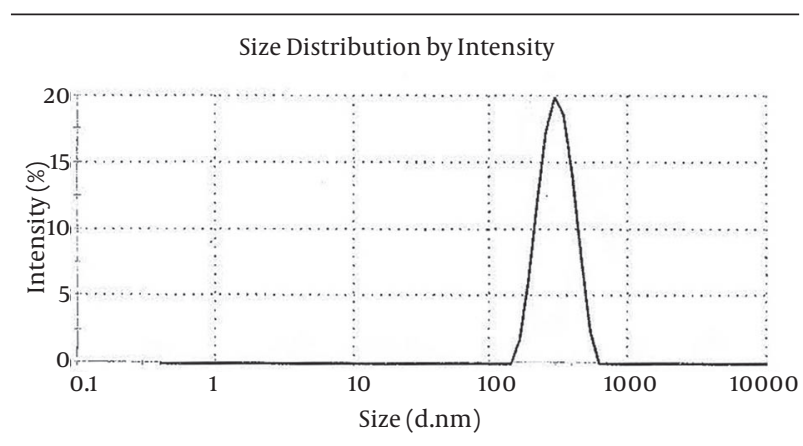

Figure 2. Zeta Potential of DNA-Chitosan Nanoparticles 
DNA $(5.2 \mu \mathrm{g})$ remained in suspension supernatant after centrifuge, DNA encapsulation was $89.6 \pm 1.2 \%$.

\subsubsection{Stability}

Stability of Eudragit L100 batch was measured at $\mathrm{pH}$ $=5.2$. This stability was related to the amount of DNA released at this $\mathrm{pH}$. Figure 3 clearly demonstrates the reasonably low release of DNA from batches, which was lower than $12 \%$ (Figure 4 ).

\subsubsection{Release Profile}

As shown in Figure 5, we can see a release of DNA form Eudragit batches in 9 hours that was more than $60 \%$. This excess of release can be really important according to transit time of particles in GI tract (Figure 3).

\subsection{Reverse Transcription Polymerase Chain Reac- tion Assay}

$\beta$-Actin band, as a positive control of RNA, approved isolated RNA quality, on which we could carry out PCR

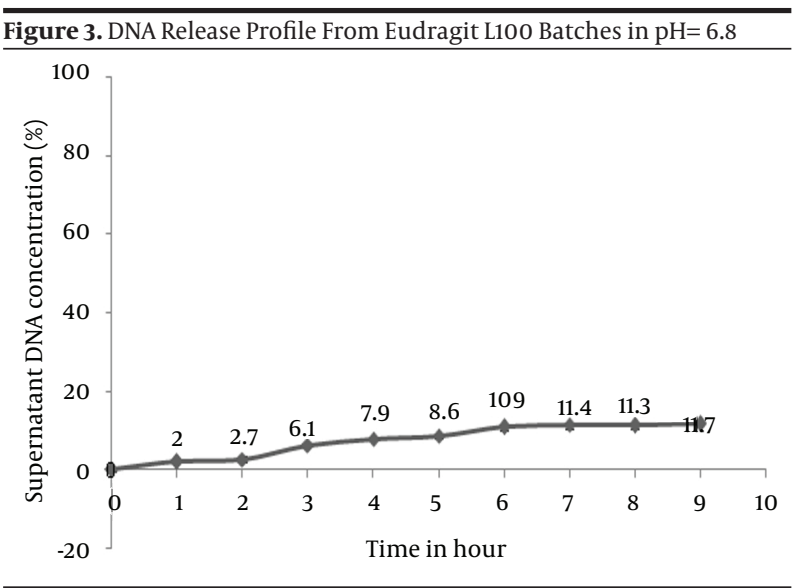

Data are presented as Mean \pm SD for $\mathrm{n}=3$ and $\mathrm{P}<0.05$.

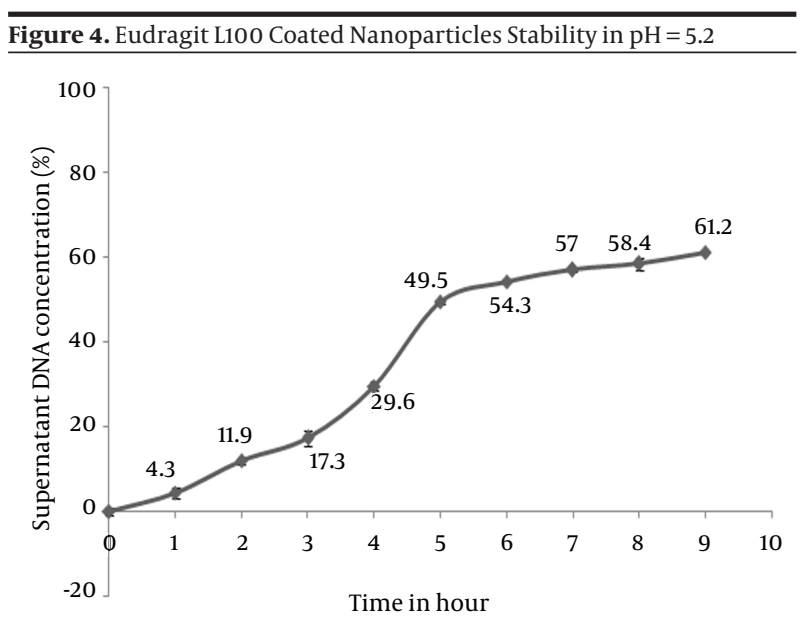

Data are presented as Mean \pm SD for $\mathrm{n}=3$ and $\mathrm{P}<0.05$. reaction of human insulin. PCR reaction of 35 cycles has produced a 437bp band of DNA standing between bands of 400 and 500 of the ladder (Figure 5).

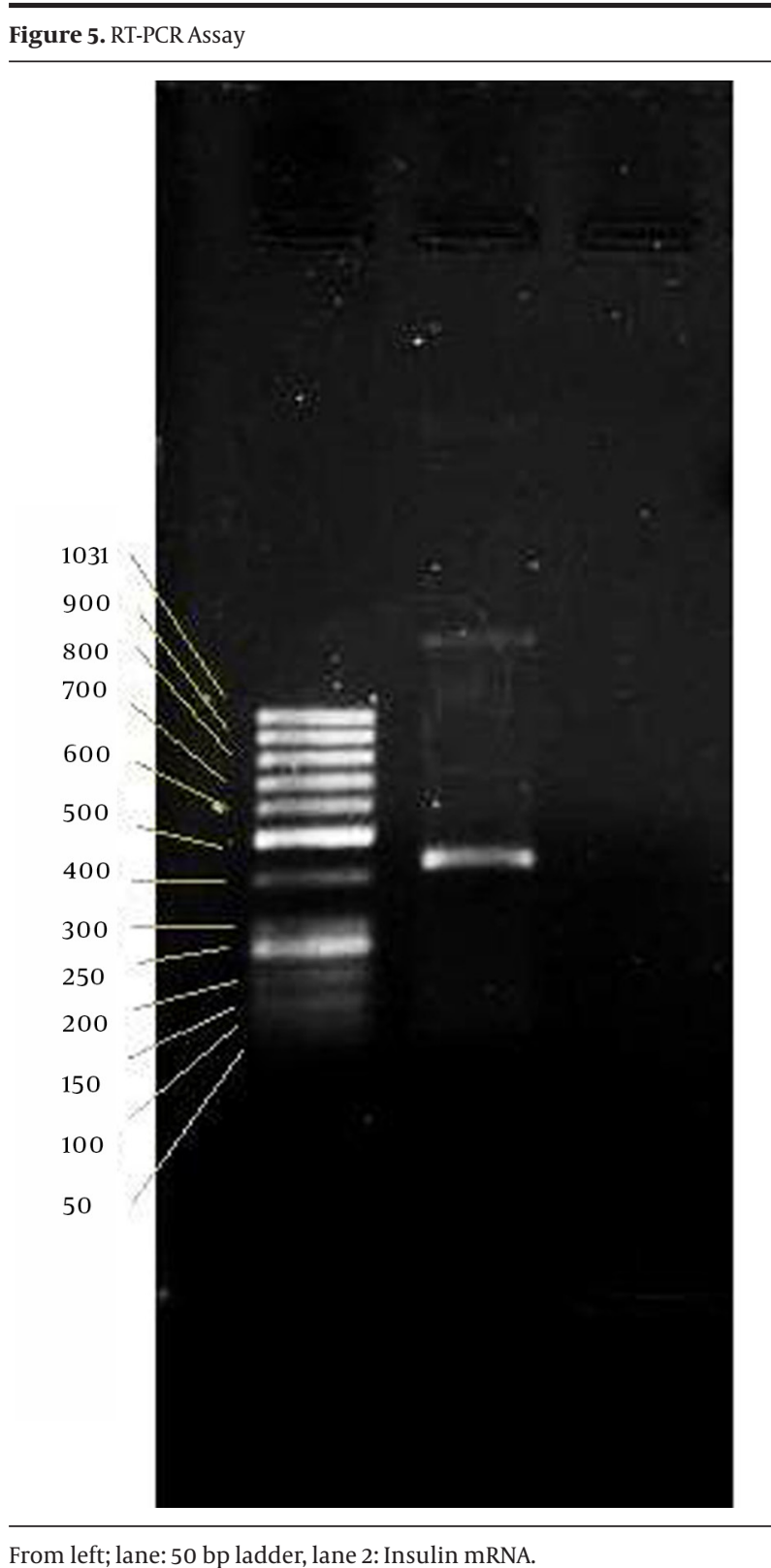

\section{Discussion}

Delivery of therapeutic materials is considered as important as therapy itself. The administration route can sometimes affect treatment outcomes and its side effects. Compliance of patient, which might not be met by invasive ways of delivery is also important because of its significant role in completing treatment duration (25). Nucleic acid is the important part of gene therapy that should be conducted at the proper place of action. Using invasive route of administration in gene therapy is 
more obvious when comparing it with other methods of therapy.

Oral delivery is the most reasonable route of administration, especially when repeated delivery is intended. This is right about gene delivery to collapsing cells of intestines $(26,27)$. DNA encounters insecure passage of GI tract by orally conducting. To conduct the nucleic acid to the proper place, different materials of wide spectrum have been used. These materials are lipids, polymers, or peptides kind that are known as nonviral delivery systems $(28,29)$. These materials compared to viral systems have been widely used because of their advantages, especially its non-immunogenicity feature.

These materials form complexes with DNA but most of these complexes, especially lipid and peptide based, are not stable enough for longer maintenance in prepared form and should be used in vivo right away. Polymers act better in this aspect. They are more interesting because of this and some other superior properties like nano size complex forming, biodegradability, and biocompatibility of their various types. Among these, some cationic polymers such as chitosan have potential of both complexing of DNA and having appropriate behavior in intestines' milieu, as well as mucoadhesivity and positive charge of prepared complexes (19). Besides, chitosan NP is a nano size system that helps in its penetrating ability. Positive zeta potential and nano size that were showed again in our study indicate long-term maintenance of NP in vitro and its efficiency to access epithelial layer.

Gel electrophoresis used for N/P ratio assigning indicated the concentration of $0.03 \%$ chitosan solution as the minimum amount to make total integrity with DNA. This finding slightly differs from previous studies that may be referred to molecular weight of employed chitosan (17, 18).

Eudragit has proved to be an appropriate choice to provide NPs with stability attributes in acidic $\mathrm{pH}$. Eudragit was applied in the delivery of other therapeutics to intestines because of this property $(1,15)$. Although Eudragit has been used in pharmaceutics industries, especially in solid drugs, using this polymer for nanoparticle coating is not usual. Some particle preparations with Eudragit have limited use in the delivery of a couple of chemical drugs and recently for therapeutic proteins. Eudragit L100 with pKa of 6 is a choice of drug delivery to intestines. Using of this polymer for delivery of gene materials gives a new insight of this polymer as a complementary polymer in gene delivery targeting intestines.

DNA encapsulation efficiency of total batch with this polymer was near $90 \%$ that was enough to save the amount of DNA being used.

In vitro evaluation of the particles was performed in 2 different $\mathrm{pHs}$ of 5.2 and 6.8. The medium with $\mathrm{pH}$ of 5.2 was used to monitor stability of particles in lower $\mathrm{pH}$ and another one with $\mathrm{pH}$ of 6.8 was used to release DNA from Eudragit batches. Release of less than $12 \%$ in $\mathrm{pH}$ of 5.2 was a sign of good stability, especially in the first hour. PH of higher than Eudragit L100 pKa raises the release of DNA to higher than 60\%. This release may be more at intestines because of harsh condition and intestines turbulence.

Transcription of delivered gene is one of the after release main steps that can verify functionality of construction. RT-PCR assay was carried out based on human insulin RNA of $437 \mathrm{bp}$. Weather internalizing of whole batch or only nano core, RT-PCR verified the existence of insulin mRNA encoded by transfected plasmid.

This system of DNA delivery has shown to have the potential of directing DNA to an appropriate place in GI tract. We can even control over the site of release by changing N/P ratio - as we saw in this study about Eudragit L100 ability in delivery of materials to upper part of intestine. Nano size of core makes the system potential for delivery of gene to the bottom of intestine crypts. Although chitosan is a mucoadhesive polymer, its application in nano size helps in penetrating through mucus. Plasmid extraction and purification are expensive steps in gene therapy. Using economical materials such as some polymers, chitosan, and Eudragit was reasonable in delivery step of therapy. The system was designed to work in vivo so application of biocompatible materials was another advantage. However, the main problem is the slow release of chitosan DNA because of its strong interaction with DNA and when the high amount of DNA is needed to present in the blood in gene therapy, the high dose should be taken.

Based on the above advantages, this noninvasive combined system for DNA delivery can help in challenging the way ahead of gene therapy toward its putting into practice.

\section{Acknowledgements}

This work was supported by Arak University of Medical Sciences. Isfahan University of Medical Sciences provided equipment. Authors would like to thank all Central Lab of Isfahan University of Medical Science' staff for their cooperation.

\section{Authors' Contributions}

Rasoul Salehi developed the original idea and the protocol, abstracted and analyzed data, wrote the manuscript, and was study supervisor and guarantor. Sedigheh Momenzadeh and Abdorrahim Sadeghi and Nasimeh Vatandoust contributed to the development of the protocol, abstracted data, analysis and interpretation of data, and prepared the manuscript.

\section{Funding/Support}

Funding sources was supported by Arak University of Medical Sciences, Arak, IR Iran (Research scholarship for Rasoul Sadeghi). Equipment and supplies were provided by Department of Genetics and Molecular Biology of Isfahan University of Medical Sciences, Isfahan, IR Iran. 


\section{References}

1. Capurso NA, Fahmy TM. Development of a pH-responsive particulate drug delivery vehicle for localized biologic therapy in inflammatory bowel disease. Yale J Biol Med. 2011;84(3):285-8.

2. Makhlof A, Tozuka Y, Takeuchi H. Design and evaluation of novel $\mathrm{pH}$-sensitive chitosan nanoparticles for oral insulin delivery. Eur JPharm Sci. 2011;42(5):445-51.

3. Patil PM, Chaudharie PD, Sahu M, Duragkar J. Review article on gene therapy. Int J Genetics. 2012;4(1):74-9.

4. Palizban AA, Salehi R, Nori N, Galehdari H. In vivo transfection rat small intestine K-cell with pGIP/Ins plasmid by DOTAP liposome. J Drug Target. 2007;15(5):351-7.

5. Heller LC, Ugen K, Heller R. Electroporation for targeted gene transfer. Expert Opin Drug Deliv. 2005;2(2):255-68.

6. Ulug P, Vasavda N, Kumar R, Keir L, Awogbade M, Cunningham $J$, et al. Hydroxyurea therapy lowers circulating DNA levels in sickle cell anemia. Am J Hematol. 2008;83(9):714-6.

7. Liu P, Santisteban I, Burroughs LM, Ochs HD, Torgerson TR, Hershfield MS, et al. Immunologic reconstitution during PEG-ADA therapy in an unusual mosaic ADA deficient patient. Clin Immunol. 2009;130(2):162-74.

8. O'Neill MJ, Bourre L, Melgar S, O'Driscoll CM. Intestinal delivery of non-viral gene therapeutics: physiological barriers and preclinical models. Drug Discov Today. 2011;16(5-6):203-18.

9. Fallingborg J. Intraluminal $\mathrm{pH}$ of the human gastrointestinal tract. Dan Med Bull.1999;46(3):183-96.

10. Fallingborg J, Christensen LA, Ingeman-Nielsen M, Jacobsen BA, Abildgaard K, Rasmussen HH. pH-profile and regional transit times of the normal gut measured by a radiotelemetry device. Aliment Pharmacol Ther.1989;3(6):605-13.

11. Mao HQ, Roy K, Troung-Le VL, Janes KA, Lin KY, Wang Y, et al. Chitosan-DNA nanoparticles as gene carriers:synthesis, characterization and transfection efficiency.J Control Release. 2001;70(3):399-421.

12. El-Sherbiny IM. Enhanced $\mathrm{pH}$-responsive carrier system based on alginate and chemically modified carboxymethyl chitosan for oral delivery of protein drugs: Preparation and in-vitro assessment. Carbohydr Polym. 2010;80(4):1125-36.

13. Kriegel C, Amiji M. Oral TNF-alpha gene silencing using a polymeric microsphere-based delivery system for the treatment of inflammatory bowel disease. J Control Release. 2011;150(1):77-86.

14. Nikam VK, Kotade KB, Gaware VM, Dhamak RTDB, Somwanshi SB, Khadse AN. Eudragit a versatile polymer: a review. Pharmacol online. 2011;1(1):152-64.

15. Lorenzo-Lamosa ML, Remunan-Lopez C, Vila-Jato JL, Alonso MJ. Design of microencapsulated chitosan microspheres for colonic drug delivery. J Control Release. 1998;52(1-2):109-18.

16. Ramshur EB, Rull TR, Wice BM. Novel insulin/GIP co-producing cell lines provide unexpected insights into Gut K-cell function in vivo.J Cell Physiol. 2002;192(3):339-50.

17. Agnihotri SA, Mallikarjuna NN, Aminabhavi TM. Recent advances on chitosan-based micro- and nanoparticles in drug delivery. $J$ Control Release. 2004;100(1):5-28.

18. Tong H, Qin S, Fernandes JC, Li L, Dai K, Zhang X. Progress and prospects of chitosan and its derivatives as non-viral gene vectors in gene therapy. Curr Gene Ther. 2009;9(6):495-502.

19. Corsi K, Chellat F, Yahia L, Fernandes JC. Mesenchymal stem cells, MG63 and HEK293 transfection using chitosan-DNA nanoparticles. Biomaterials. 2003;24(7):1255-64.

20. Rao JP, Geckeler KE. Polymer nanoparticles: Preparation techniques and size-control parameters. Prog Polym Sci. 2011;36(7):887-913.

21. Khamanga SM, Parfitt N, Nyamuzhiwa T, Haidula H, Walker RB. The Evaluation of Eudragit Microcapsules Manufactured by Solvent Evaporation Using USP Apparatus 1. Dissolution Technol. 2009;16(2):15-22.

22. Peltonen L, Koistinen P, Karjalainen M, Hakkinen A, Hirvonen $J$. The effect of cosolvents on the formulation of nanoparticles from low-molecular-weight poly(l)lactide. AAPS PharmSciTech. 2002;3(4):E32.

23. Liao ZX, Peng SF, Ho YC, Mi FL, Maiti B, Sung HW. Mechanistic study of transfection of chitosan/DNA complexes coated by anionic poly(gamma-glutamic acid). Biomaterials. 2012;33(11):330615.

24. Chomczynski P, Sacchi N. Single-step method of RNA isolation by acid guanidinium thiocyanate-phenol-chloroform extraction. Anal Biochem. 1987;162(1):156-9.

25. Lamprecht A, Yamamoto H, Takeuchi H, Kawashima Y. A pH-sensitive microsphere system for the colon delivery of tacrolimus containing nanoparticles. J Control Release. 2005;104(2):337-46.

26. Nograles N, Abdullah S, Shamsudin MN, Billa N, Rosli R. Formation and characterization of pDNA-loaded alginate microspheres for oral administration in mice. J Biosci Bioeng. 2012;113(2):133-40.

27. Bhavsar MD, Amiji MM. Oral IL-10 gene delivery in a microspherebased formulation for local transfection and therapeutic efficacy in inflammatory bowel disease. Gene Ther. 2008;15(17):1200-9.

28. Bhavsar MD, Amiji MM. Polymeric nano- and microparticle technologies for oral gene delivery. Expert Opin Drug Deliv. 2007;4(3):197-213.

29. Morille M, Passirani C, Vonarbourg A, Clavreul A, Benoit JP. Progress in developing cationic vectors for non-viral systemic gene therapy against cancer. Biomaterials. 2008;29(24-25):3477-96. 